\title{
Feasibility analysis of GNSS-based ionospheric observation on a fast-moving train platform (GIFT)
}

\author{
Shiwei Yu and Zhizhao Liu* (1)
}

\begin{abstract}
The ionospheric effect plays a crucial role in the radio communications. For ionospheric observing and monitoring, the Global Navigation Satellite System (GNSS) has been widely utilized. The ionospheric condition can be characterized by the Total Electron Contents (TEC) and TEC Rate (TECR) calculated from the GNSS measurements. Currently, GNSS-based ionospheric observing and monitoring largely depend on a global fiducial network of GNSS receivers such as the International GNSS Service (IGS) network. We propose a new approach to observe the ionosphere by deploying a GNSS receiver on a Hong Kong Mass Transit Railway (MTR) train. We assessed the TECR derived from the MTR-based GNSS receiver by comparing it with the TECR derived from a static GNSS receiver. The results show that the Root-Mean-Squares (RMS) errors of the TECR derived from the MTR-based GNSS receiver is consistently approximately 23\% higher than that derived from the static GNSS receiver. Despite the increased error, the findings suggest that the GNSS observation on a fast-moving platform is a feasible approach to observe the ionosphere over a large region in a rapid and cost-effective way.
\end{abstract}

Keywords: Global navigation satellite system (GNSS), Total electron contents (TEC), TEC rate (TECR), Fast-moving train platform

\section{Introduction}

The ionosphere has a significant impact on satellitebased navigation and positioning. Due to the abundance of charged particles in the ionosphere, radio signals experience phase fluctuations, amplitude fluctuations, group delay, absorption, scattering, and frequency shifts when they travel through the ionosphere (Bernhardt et al., 2006; Chen et al., 2008). As a result, the Earth observation systems, such as the Global Navigation Satellite Systems (GNSS), the Doppler Orbit and Radio Positioning Integration by Satellite (DORIS), are adversely affected by the ionospheric situation (Aquino et al., 2005; Sreeja et al., 2011). Fortunately, the ionospheric situation can be characterized by the Total Electron Contents (TEC) (Davies,

*Correspondence: Iszzliu@polyu.edu.hk

Department of Land Surveying and Geo-Informatics, The Hong Kong

Polytechnic University, Kowloon, Hong Kong, People's Republic of China
1990), and the GNSS measurements can be used to compute the ionospheric TEC (Arikan et al., 2003). Therefore, the in-situ ionospheric situation along the GNSS signal paths can be manifested in the TEC variations. A considerable number of studies have been conducted to analyze the ionospheric anomalies during powerful solar and geomagnetic space weather based on the GNSS TEC (Aarons \& Lin, 1999; Adeniyi et al., 2014; Chen et al., 2017; Tariku, 2015). Furthermore, ionospheric irregularities during tropical cyclones and earthquakes have been studied by analyzing the GNSS TEC (Jin et al., 2015; Yang \& Liu, 2016a).

The TEC Rate (TECR or Rate of TEC (ROT)) was first introduced to study ionospheric irregularities (Wanninger, 1993). The TECR can be retrieved by differentiating the TEC between two consecutive observations. Compared with the TEC, the TECR provides a more direct and informative description of the ionospheric 
situation in the time domain (Mendillo et al., 2000; Pi et al., 1997). Moreover, the computation of the TECR is more efficient as it directly cancels the hardware delays of GNSS satellites and receivers (Cai et al., 2013; Liu, 2011). Benefiting from the GNSS TECR, the ionospheric situation can be well monitored. Recently, the GNSS TECR has become a research focus for studying the ionosphere (Kong et al., 2017; Yang \& Liu, 2016a, 2016b). In addition, the study of the TECR can also contribute to the GNSS data quality analysis and control as the TECR information is very decisive in carrier phase cycle slip detection and repair (Liu, 2011).

To monitor the ionospheric condition on a global scale, the International GNSS Service (IGS) network stations have been utilized to produce the Global Ionosphere Maps (GIMs) (Feltens, 2007; GhoddousiFard et al., 2011; Hernández-Pajares et al., 2009; Li et al., 2015; Mannucci et al., 1998; Orús et al., 2005; Schaer, 1999). The IGS GIMs usually model the global TEC over each grid point with a spatial resolution of $5^{\circ} \times 2.5^{\circ}$ in longitude and latitude, and a temporal resolution of $15 \mathrm{~min}$ to $2 \mathrm{~h}$ (Hernández-Pajares et al., 2017; Orús et al., 2005; Roma-Dollase et al., 2018). Recently, many efforts have been made to improve the IGS GIMs products, e.g. real-time products with a temporal resolution of $15 \mathrm{~min}$ (Li et al., 2020). However, the spatial resolution of the IGS GIMs are inadequate to observe the small-scale ionospheric situation. Moreover, its performance is reduced in some regions due to the sparse distribution of GNSS stations. Therefore, various regional GNSS networks, such as Wide Area Augmentation System (WAAS) in North America, the European Geostationary Navigation Overlay Service (EGNOS) in Europe, the Multi-functional Satellite Augmentation System (MSAS) in Japan, the Global Positioning System (GPS) Aided Geosynchronous Equatorial Orbit (GEO) Augmented Navigation (GAGAN) in India, and the Crustal Movement Observation Network of China (CMONOC), have been used to study the ionospheric condition in a more precise way with a higher spatial resolution. Liu and Gao (2004) proposed the methods of 2D grid-based and 3D tomography-based ionospheric modeling using the regional GPS networks, such as the Swedish Network of Permanent GPS Reference Stations (SWEPOS) and the South California Integrated GPS Network (SCIGN). In addition, Opperman et al. (2007) developed a regional ionospheric TEC model with $0.5^{\circ} \times 0.5^{\circ}$ spatial resolution based on GPS data in South Africa. Bergeot et al. (2014) proposed a near real-time ionospheric monitoring method using the European Reference Frame (EUREF) Permanent Network (EPN), and the spatial resolution was $0.5^{\circ} \times 0.5^{\circ}$ in longitude and latitude. Lastly, Yang et al.
(2016) exploited the 260 CMONOC GNSS stations to study the 3D ionospheric structure over China.

However, all these ionospheric studies, either on a global scale or on a regional scale, depend on the availability of GNSS reference stations, and the density of GNSS stations is still not sufficient, particularly in many rural or remote areas. In those areas with data holes or data insufficiency, the ionosphere is poorly characterized. Hence, we propose the idea of deploying GNSS receivers on the trains in the nation-wide railway network as a new method to complement the traditional GNSS monitoring networks for TECR observations. We investigate the feasibility of TECR observation using a GNSS receiver deployed on a fast-moving train, namely the Hong Kong Mass Transit Railway (MTR) train. The MTR-based TECR observations are assessed by comparing them with those derived from a static GNSS receiver installed nearby the MTR railway line. This proposed approach has the advantage of a cost-effective and dynamic TECR observation over a large area. It can compensate for the ground-based GNSS networks, which usually have a very low spatial resolution in the rural or remote areas (Grejner-Brzezinska et al., 2007; Li et al., 2014).

In the following sections, we first describe the data and methodology used to retrieve the ionospheric TECR from an MTR-based GNSS receiver. Then, the properties of the MTR-based TECR are analyzed and assessed by comparing it with the TECR obtained from a static GNSS receiver. Finally, a comprehensive conclusion is provided.

\section{Data and methodology}

The GNSS data were collected from an experiment conducted in Hong Kong on 19 June 2017. One GNSS receiver, as a Moving Station (MS), was set up on a Hong Kong MTR train, as shown in Fig. 1a. It should be pointed out that the window glass of the train will affect the quality of the GNSS measurements (Liu et al., 2020). The other GNSS receiver, as a Static Station (SS), was deployed in the open space nearby the MTR train railway line, as depicted in Fig. $1 \mathrm{~b}$.

Figure 2 depicts the spatial distribution of the MTR railway line and SS receiver. The green circle with a cross denotes the position of the SS receiver, the red line with train marks represents the MTR railway line segment with a distance of about $3.1 \mathrm{~km}$. The MTR railway line and SS receiver were carefully selected so that GNSS satellite signals are minimally affected by surrounding buildings and mountains. The length of the selected MTR railway line, running between the Shek Mun Station and the Tai Shui Hang Station, is around $3.1 \mathrm{~km}$. The SS receiver is in the middle of the selected railway line, and it is about $50 \mathrm{~m}$ far away from the railway tracks.

The MS receiver on the MTR train was placed near the window inside the train compartment. When the MTR 

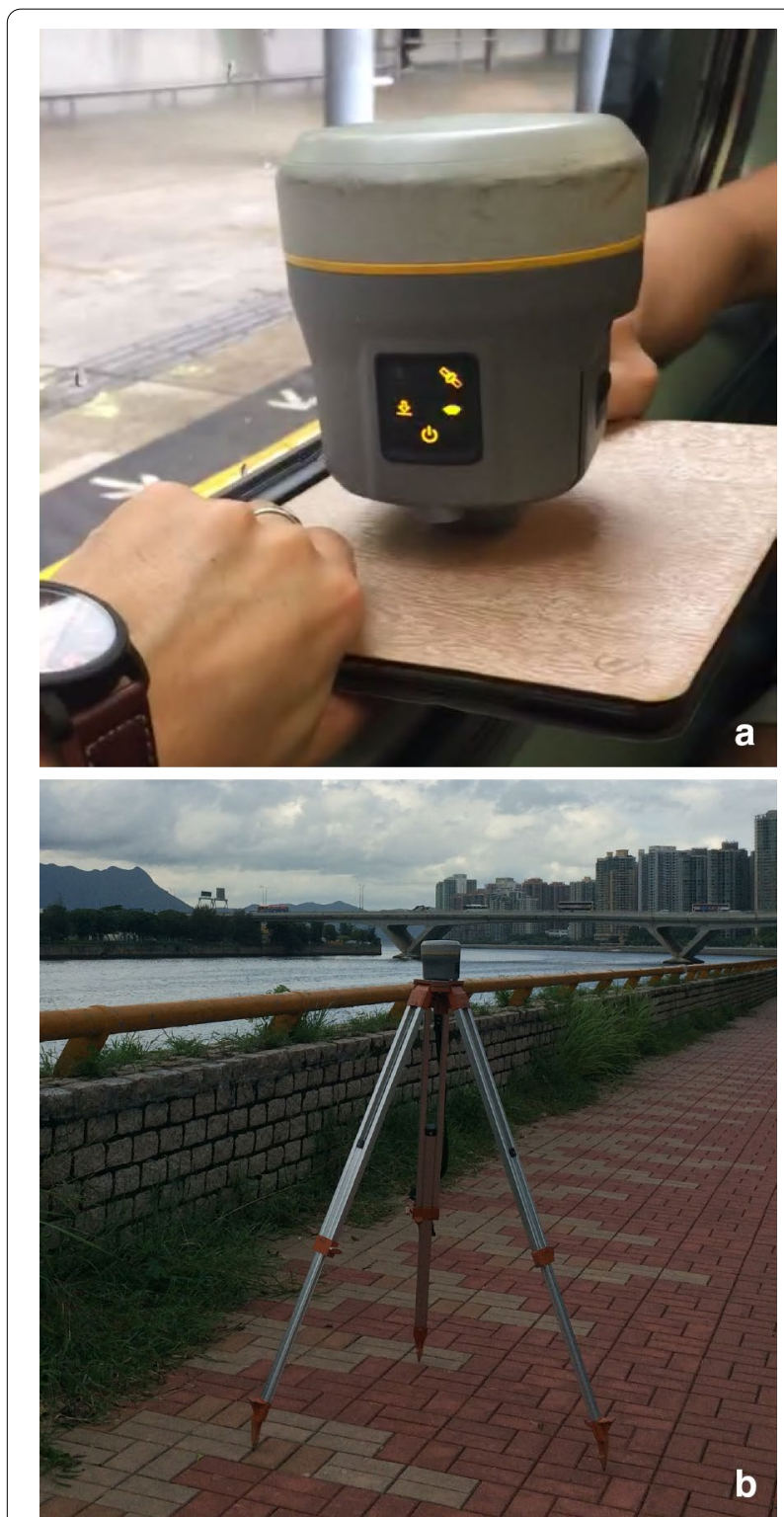

Fig. 1 a The moving station deployed beside the window in the MTR train and $\mathbf{b}$ the static station deployed beside the MTR train line. They were equipped with the same receiver type: the Trimble R10 receivers

train traveled northbound from the Shek Mun Station to the Tai Shui Hang Station or southbound from the Tai Shui Hang Station to the Shek Mun Station, the MS receiver was always put at the same side where the SS receiver is located (left side in Fig. 2). The data was collected for around 80 min from 15:08 to 16:28 Hong Kong Time (HKT) on 19 June 2017. It took the MTR train approximately 5 min to run between the two stations and one data file was generated for each journey. Ten sets of GNSS data were recorded by the MS receiver, but four of them were not used in this study due to their poor data quality. The poor data quality

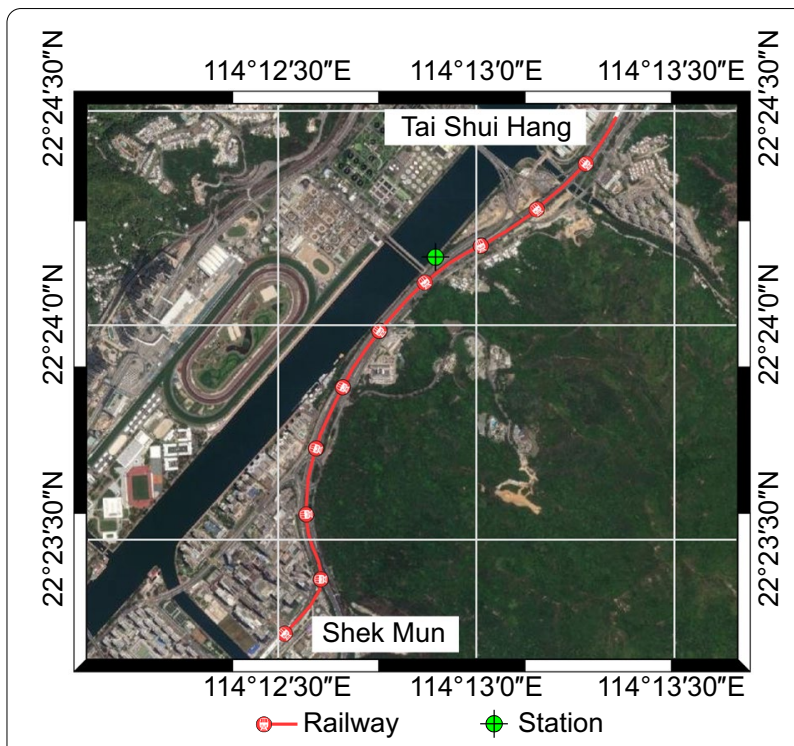

Fig. 2 Spatial distribution of the SS receiver and the MTR railway line where the MS receiver was placed

may be caused by the complex observation environment, like obstructions, window glass, and unpredictable artificial factors. Therefore, we cannot guarantee that all the data sets have the same quality. In addition, there is a break of about $4 \mathrm{~min}$ between two journeys due to the waiting time for the next train.

Both the MS and SS receivers were equipped with Trimble R10 of the same parameter configuration. The elevation cutoff angle was set to zero to track as many GNSS satellites as possible. The GPS, GLObal Navigation Satellite System (GLONASS), Galileo navigation satellite system (Galileo) and BeiDou Navigation Satellite System (BDS) were used in this study. The sample rate was set to $20 \mathrm{~Hz}$. The spatial ionospheric gradient under this sample rate can be negligible (Vuković \& Kos, 2016).

According to the GNSS pseudorange and carrier phase measurements, the observations formula can be written as the following (Leick et al., 2015):

$$
\begin{aligned}
R_{\mathrm{i}}^{\mathrm{s}}= & \rho^{\mathrm{s}}+c \cdot\left(\mathrm{d} t-\mathrm{d} T^{s}\right)+T+I_{i} \\
& -\left(b_{i, R}+B_{i}^{s, R}\right)+M_{i, R}+\varepsilon_{i, R} \\
\lambda_{i} \Phi_{i}^{s}= & \rho^{s}+c \cdot\left(\mathrm{d} t-\mathrm{d} T^{s}\right)+T-I_{i}+\lambda_{i} N_{i}^{s} \\
& -\left(b_{i, \Phi}+B_{i}^{s, \Phi}\right)-\left(w_{i, \Phi}+W_{i}^{s, \Phi}\right)+M_{i, \Phi}+\varepsilon_{i, \Phi}
\end{aligned}
$$

where $R$ and $\Phi$ denote the pseudorange and carrier phase measurements, respectively the units for $R$ and $\Phi$ are meter and cycle, respectively. $\lambda_{i}$ is the wavelength 
of carrier phase measurement in meter. the superscript $s$ denotes the GNSS satellite. the subscript $i$ is the frequency number, such as $i=1$ for the GPS L1 signal, $i=2$ for the GPS L2 signal. $\rho$ is the geometrical distance between the receiver and the satellite in meter. $\mathrm{dt}$ and $\mathrm{dT}^{\mathrm{s}}$ are the clock errors of the receiver and satellite in second, respectively. $c$ is the speed of light in vacuum in $\mathrm{m} / \mathrm{s}$. $I$ is the ionospheric range delay in meter, $T$ is the tropospheric range delay in meter. $N$ is the integer ambiguity. $b_{i, R}$ and $b_{i, \Phi}$ are the hardware delay of the receiver on the pseudorange and carrier phase measurements, respectively, in meter. $B^{s, R}$ and $B^{s, \Phi}$ in meter are the hardware delay of the satellite on the pseudorange and carrier phase measurements, respectively. $w_{i, \Phi}$ and $W_{i}^{s, \Phi}$ in meter are phase windup terms at the receiver and satellite, respectively. The windup terms in the phase polarized signals due to the moving platform are neglected in this study. $M_{i, R}$ and $M_{i, \Phi}$ are the multipath error on the pseudorange and carrier phase measurements, respectively. $\varepsilon_{i, R}$ and $\varepsilon_{i, \Phi}$ signify the noise on the pseudorange and carrier phase measurements, respectively.

Assuming the multipath errors and observation noise are of equal values on two frequencies, the ionospheric TEC from dual-frequency pseudorange measurements can be retrieved as the following:

$$
T E C_{R}=\frac{f_{1}^{2}\left[R_{1}^{s}-R_{2}^{s}+\left(b_{1, R}-b_{2, R}\right)+\left(B_{1}^{s, R}-B_{2}^{s, R}\right)\right]}{40.3 \times 10^{16}(1-\gamma)}
$$

where the term $\gamma$ is calculated as:

$$
\gamma=\frac{f_{1}^{2}}{f_{2}^{2}}
$$

TECR can be calculated by differentiating the TEC values retrieved from two consecutive epochs. The TECR equation can be written as below:

$$
T E C R_{R}=\frac{T E C_{R}(k)-T E C_{R}(k-1)}{\Delta t}
$$

where $\operatorname{TEC}_{R}(\cdot)$ is the TEC value on the pseudorange measurements at a given epoch; $\Delta t$ is the data sampling interval. Assuming the hardware delays of the receiver and satellite are constants for a short duration, the TECR equation on the pseudorange measurements can be simplified as below:

$$
\begin{aligned}
& \operatorname{TECR}_{R}(k)=\frac{f_{1}^{2}}{40.3 \times 10^{16}(1-\gamma) \Delta t} \\
& {\left[R_{1}^{s}(k)-R_{2}^{s}(k)-R_{1}^{s}(k-1)+R_{2}^{s}(k-1)\right]}
\end{aligned}
$$

Similarly, the TECR on the carrier phase measurements can be derived as a similar equation:

$$
\begin{aligned}
\operatorname{TECR}_{\Phi}(k)= & \frac{f_{1}^{2}}{40.3 \times 10^{16}(\gamma-1) \Delta t}\left\{\lambda_{1}\left[\Phi_{1}^{s}(k)-\Phi_{1}^{s}(k-1)\right]\right. \\
& \left.-\lambda_{2}\left[\Phi_{2}^{s}(k)-\Phi_{2}^{s}(k-1)\right]\right\}
\end{aligned}
$$

It should be noted that the TECR on carrier phase measurements is calculated under the condition of no cycle slips between the two consecutive epochs. In other words, cycle slip detection and repair should be performed prior to the calculation of TECR on carrier phase measurements. The well-performed algorithms of cycle slip detection and repair used in this study are proposed by Cai et al. (2013). In addition, if the Doppler measurements are available in GNSS measurements, the Doppler-aided cycle slip detection and repair can be also utilized, particularly for such high-rate GNSS observations (Zhao et al., 2020).

\section{IPP spatial distance due to moving platform}

The GNSS TECR calculated from the SS receiver contains the spatial gradient information due to the motion of GNSS satellites. Regarding the MS receiver, the spatial gradient is a function of the motions of both GNSS satellites and the MTR train. The clear geometric relationship between the ground motion point and the corresponding Ionospheric Pierce Point (IPP), which is the intersection between the GNSS signal path and the ionospheric single layer (Schaer, 1999), is shown in Fig. 3.

The geometric relationship can be written as below:

$$
\frac{D}{d}=\frac{H-h}{H}
$$

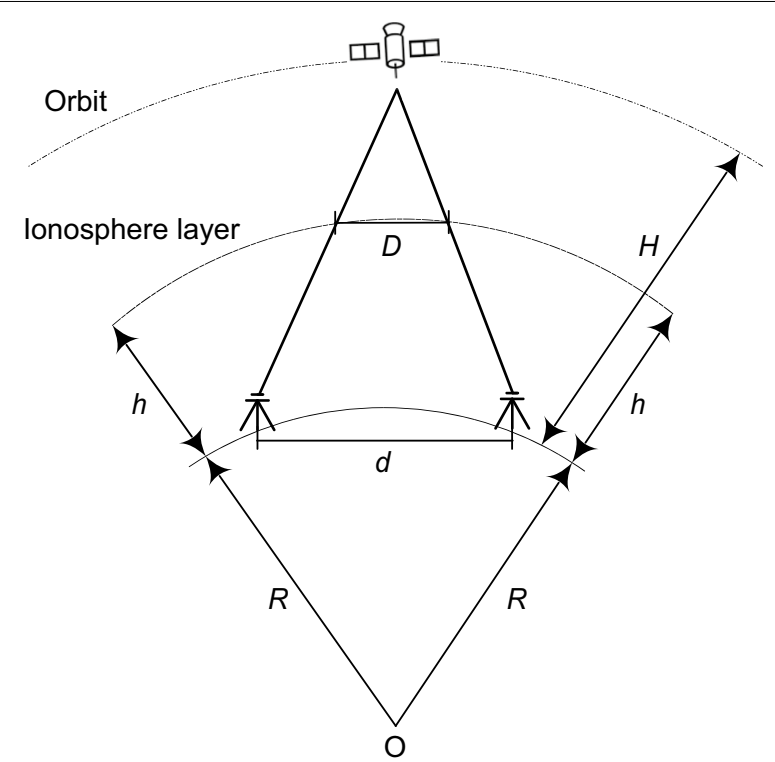

Fig. 3 Geometric relationship between the ground motion points and IPPS 
where $d$ is the ground distance between the two MTR railway stations, which is about $3.1 \mathrm{~km}$; $D$ is the distance between two pierce points on the ionospheric single layer corresponding to the two stations on the ground; $H$ denotes the orbit height of the satellite, i.e. $20,100 \mathrm{~km}$ for GPS satellites; and $h$ denotes the height of the ionospheric single layer, i.e. $350 \mathrm{~km}$; $\mathrm{O}$ and $R$ represent Earth mass center and radius, respectively.

Therefore, the spatial distance on the ionospheric single layer due to the train's movement can be calculated. The distance of the two subway stations on the ionospheric single layer, after mapping the ground distance of about $3.1 \mathrm{~km}$ to the ionospheric layer, is about $3.0 \mathrm{~km}$. the accuracy of pseudorange and carrier phase measurements for six typical models of receivers. It is clear that the accuracy of pseudorange measurements for these receivers is around a few decimeters, and the accuracy of carrier phase measurements is higher than one millimeter.

We assume that all the pseudorange measurements have equal accuracy, and their variances are denoted as $\delta_{R}^{2}$. In addition, the measurements at epochs $(k)$ and $(k-1)$ are independent. According to the error propagation law, the accuracy of the TECR values derived from the pseudorange measurements can be estimated with the following equation:

$$
m_{T E C R_{R}}= \pm \sqrt{\left(\frac{\partial f}{\partial R_{1}^{S}(k)}\right)^{2} \delta_{R}^{2}+\left(\frac{\partial f}{\partial R_{2}^{S}(k)}\right)^{2} \delta_{R}^{2}+\left(\frac{\partial f}{\partial R_{1}^{S}(k-1)}\right)^{2} \delta_{R}^{2}+\left(\frac{\partial f}{\partial R_{2}^{S}(k-1)}\right)^{2} \delta_{R}^{2}}
$$

In addition, taking the average speed of the train, e.g. around $38 \mathrm{~km} / \mathrm{h}$ provided by the MTR company, into consideration, it is about $10.4 \mathrm{~m}$ on the ionospheric layer for each second under the assumption of satellite being stationary. The distance between IPPs in one second for a moving satellite (with the speed of around $4 \mathrm{~km} / \mathrm{s}$ ) is approximately $70.0 \mathrm{~m}$ with respect to a stationary station on the ground. Therefore, the spatial distance caused by the movement of the train (with speed of about $38 \mathrm{~km} / \mathrm{h}$ ) is at the same order with that caused by the movement of satellites.

\section{Accuracy analysis of TECR observations}

Currently, most GNSS receivers can produce high-quality measurements of both pseudorange and carrier phase. In detail, carrier phase can be measured with the accuracy of around $1.0 \mathrm{~mm}$ or even higher, and pseudorange measurements have the accuracy of around $30.0 \mathrm{~cm}$ or even higher (Czerniak \& Reilly, 1998). Table 1 summarizes where $m_{T E C R_{R}}$ is the accuracy of the TECR derived from pseudorange measurements; $f$ denotes the TECR function. The accuracy of the TECR derived from pseudorange and carrier phase measurements can be estimated as:

$$
\begin{aligned}
& m_{T E C R_{R}}= \pm \frac{\sqrt{4} \times f_{1}^{2}}{40.3 \times 10^{16}(1-\gamma) \Delta t} \delta_{R} \\
& m_{T E C R_{\Phi}}= \pm \sqrt{2}\left(\frac{f_{1}^{2}}{40.3 \times 10^{16}(\gamma-1) \Delta t}\right) \sqrt{\left(\lambda_{1}^{2}+\lambda_{2}^{2}\right)} \delta_{\Phi}
\end{aligned}
$$

The accuracy of GNSS TECR values is shown in Table 2. It should be noted that the examples for the GLONASS in Table 2, i.e., row 2 and 6, are calculated for the GLONASS carrier base frequency considering its Frequency Division Multiple Access (FDMA) mode.

Table 1 Typical accuracy of pseudorange and carrier phase measurements of typical receiver models from major GNSS receiver manufacturers

\begin{tabular}{lcccc}
\hline Receiver type & \multicolumn{2}{c}{ Accuracy index of GPS } & & \multicolumn{2}{c}{ Accuracy index of GLONASS } \\
\cline { 2 - 3 } & Code $(\mathbf{c m})$ & Carrier $(\mathbf{m m})$ & Code $(\mathbf{c m})$ & 2.0 \\
\hline Leica GR10/GR25 & 2.0 & 0.2 & 10.0 & Carrier $(\mathbf{m m})$ \\
JAVAD TRE-G3TH Delte3 & 10.0 & 1.0 & $<10.0$ & 0.2 \\
Trimble NetR8/R9 & $<10.0$ & $<1.0$ & 8.0 & 1.0 \\
NovAtel OEM7 & 8.0 & 0.5 & 25.0 & 1.0 \\
PolaRx5 & 16.0 & $1.0-1.3$ & 1.0 & 1.3 \\
\hline
\end{tabular}


Table 2 The accuracy of the TECR obtained from the pseudorange and carrier phase measurements of different GNSS systems.

\begin{tabular}{lllllll}
\hline No & Frequency & $\boldsymbol{f}_{\mathbf{1}}(\mathbf{M H z})$ & $\boldsymbol{\gamma}$ & $\boldsymbol{\delta}(\mathbf{m})$ & $\boldsymbol{\Delta t}(\mathbf{s})$ & $\boldsymbol{m}_{\text {TECR }}$ in TECU/sec \\
\hline 1 & 1575.420 & 1.64694 & 0.3 & 0.05 & \pm 114.235 \\
2 & GPS L1, L2 & 1602.000 & 1.65306 & 0.3 & 0.05 & \pm 117.017 \\
3 & GLONASS L1, L2 & 1575.420 & 1.79327 & 0.3 & 0.05 & \pm 93.164 \\
4 & Galileo E1, E2 & 1561.098 & 1.67242 & 0.3 & 0.05 & \pm 107.919 \\
5 & BDS B1, B2 & 1575.420 & 1.64694 & 0.001 & 0.05 & \pm 0.381 \\
6 & GPS L1, L2 & 1602.000 & 1.65306 & 0.001 & 0.05 & \pm 0.390 \\
7 & GLONASS L1, L2 & 1575.420 & 1.79327 & 0.001 & 0.05 & \pm 0.311 \\
8 & Galileo E1, E2 & 1561.098 & 1.67242 & 0.001 & 0.05 & \pm 0.360 \\
\hline
\end{tabular}

TECU/sec represents total electron content unit (TECU) per second
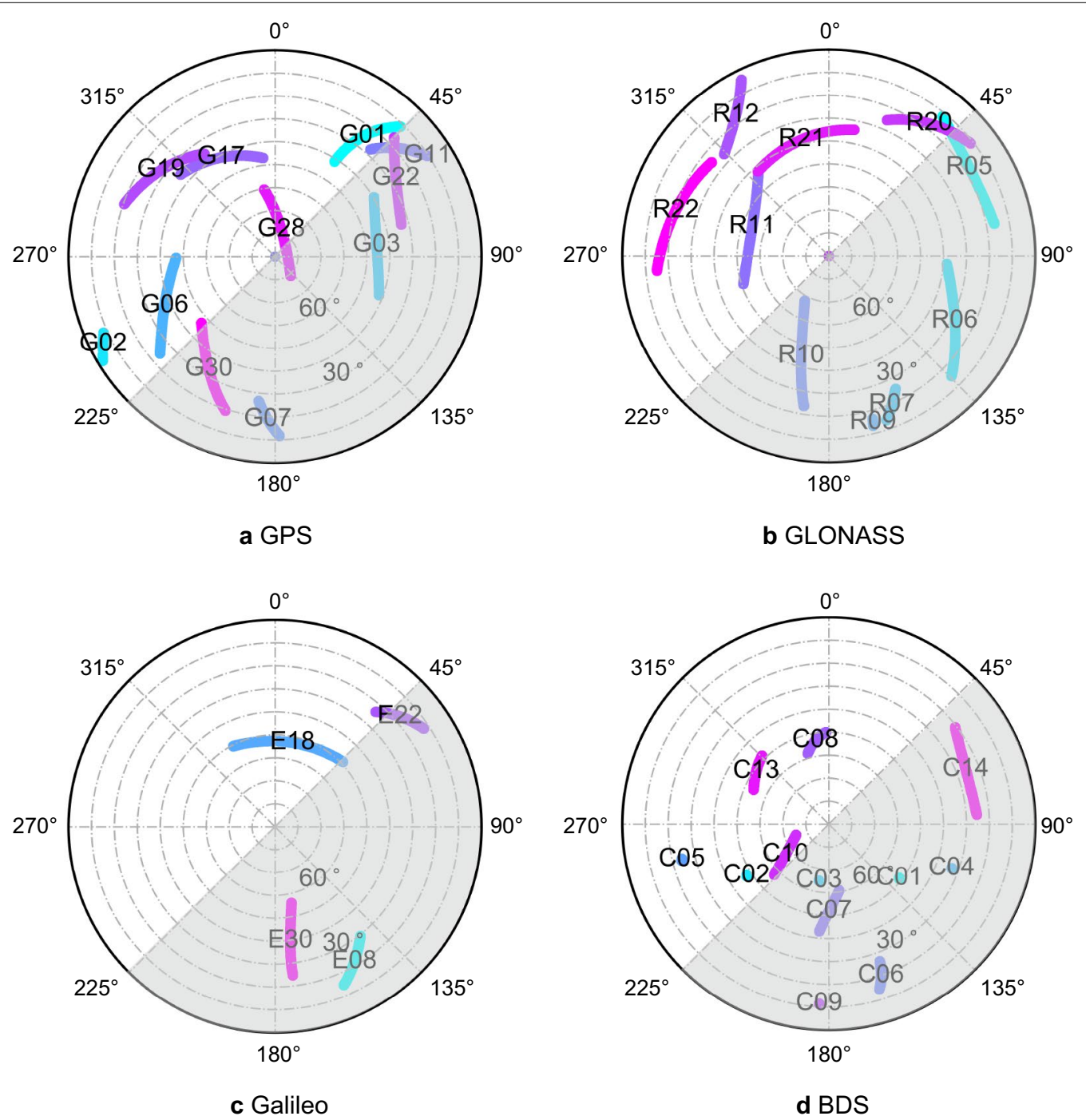

Fig. 4 Satellite distribution in sky view for different GNSS systems, i.e., GPS in (a), GLONASS in (b), Galileo in (c), and BDS in (d). Its time duration is from 15:08 to 16:28 HKT on 19 June 2017. The gray mask indicates that satellites in the mask are not visible for the moving station 


\section{Results and discussions}

The GNSS satellites above the SS and MS receivers during the test period share the same spatial distribution because of the short distance between the two stations. The satellite sky views for the GPS, GLONASS, Galileo, and BDS at the SS receiver are shown in Fig. $4 a-d$,. The gray mask represents the signal obstruction area for the MS receiver onboard the MTR train, which means the satellites in this area are not visible for the MS receiver. The mask has an azimuth angle of about $45^{\circ}$, which is consistent with the MTR railway orientation in Fig. 2. It should be noted that only single-frequency data were observed from the GLONASS R12 satellite. Therefore, this satellite will be excluded from the following analysis.

\section{TECR analysis}

The TECR values retrieved from the pseudorange and carrier phase measurements are evaluated in this section. Figure 5 demonstrates the overall TECR values derived from the SS receiver. For display purposes, the TECR values in Fig. 5, however, have been downsampled by 20 times to a rate of $1 \mathrm{~Hz}$.

In Fig. 5a, the TECR accuracy on the pseudoranges, about $250 \mathrm{TECU} / \mathrm{sec}$, is apparently overestimated compared with the theoretical accuracy, about $100 \mathrm{TECU} / \mathrm{sec}$, presented in Table 2, while the TECR accuracy on the carrier phase, around $0.4 \mathrm{TECU} / \mathrm{sec}$, is consistent with the theoretical value presented in Table 2. The overestimation of the pseudorange TECR is due to the large thermal noise and multipath effect on the pseudorange measurements. In addition, some anomalies are present in the carrier-phase-derived TECR from GPS satellites in Fig. 5a. They are mainly caused by measurement noise under a clear geomagnetic and solar condition. The geomagnetic and solar conditions are represented by Kp, Dst, and F10.7 indices in the Fig. 6, where Kp is less than 3 (Mungufeni et al., 2016), Dst is larger than -20 nT (Gulyaeva \& Arikan, 2017), and F10.7 is less than $80 \mathrm{sfu}$ (solar flux units) (Tapping, 2013). All the indices imply a clear geomagnetic and solar condition on the experiment day.

The GNSS signals tracked by the MS receiver must pass through the windows of the MTR train. Therefore, the observation condition is much worse than the opensky circumstance. The TECR values derived from the MS receiver are displayed in Fig. 7. Figure 5 shows that the TECR results from pseudorange measurements have a significantly lower accuracy than those of carrier phase measurements. We therefore just focus on carrier phasederived TECR only for the moving receiver.

The results show that the TECR values at the beginning of every journey have a small variation because of a low moving speed. An obvious gap can be observed for every journey, that is because GNSS satellite signals are blocked by station buildings when the train passes through the MTR station. Most of the TECR values for

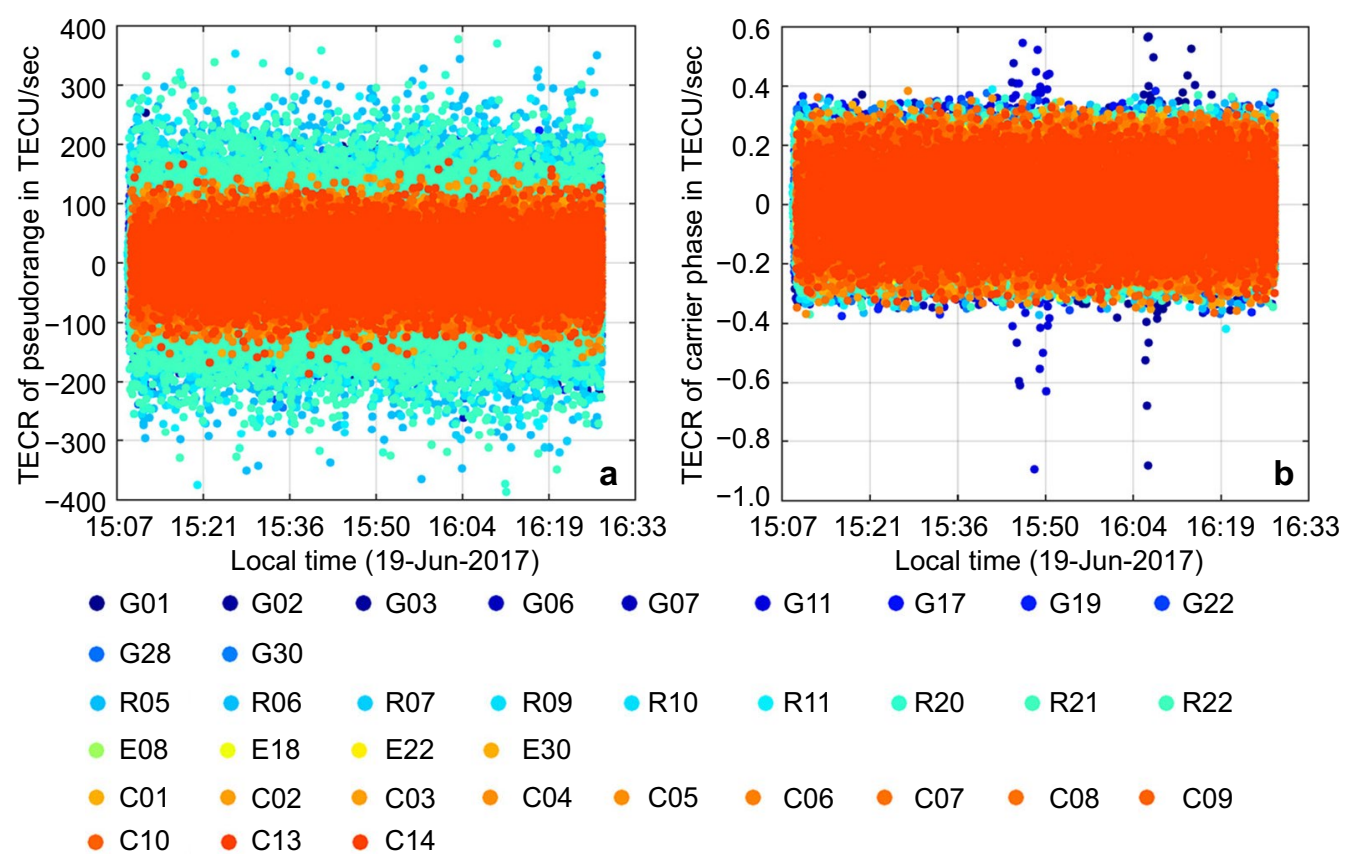

Fig. 5 TECR derived from pseudorange (a) and carrier phase measurements (b) from GNSS satellites (GPS, GLONASS, Galileo, and BDS). The data were collected at the SS receiver beside the MTR railway line from 15:08 to 16:28 HKT on 19 June 2017 

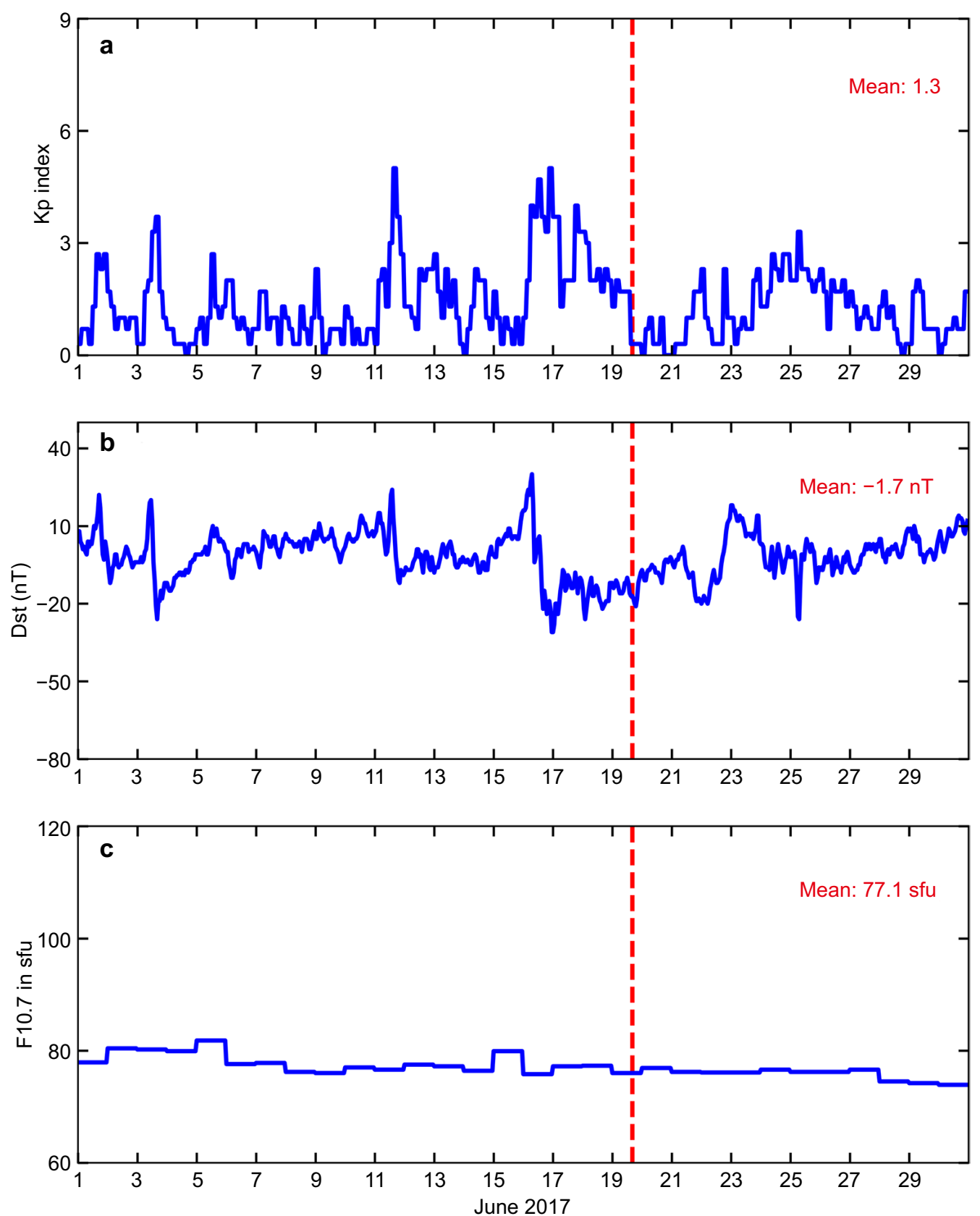

Fig. 6 The geomagnetic indices, i.e. Kp (a), Dst (b), and solar index F10.7 (c) in June 2017. The red vertical dashed line denotes the experiment time at 16:00 HKT on 19 June 2017

GPS, GLONASS, Galileo, and BDS fluctuate within \pm 1 TECU/sec. However, there are a considerable number of TECR outliers for every journey. The details to deal with these anomalies will be discussed in the following section.

\section{Outlier analysis}

Figure 8 shows the TECR values of the six satellites selected from six journeys. The satellites were randomly selected from the six datasets. The results show that TECR values derived from six different satellites are basically stable in 

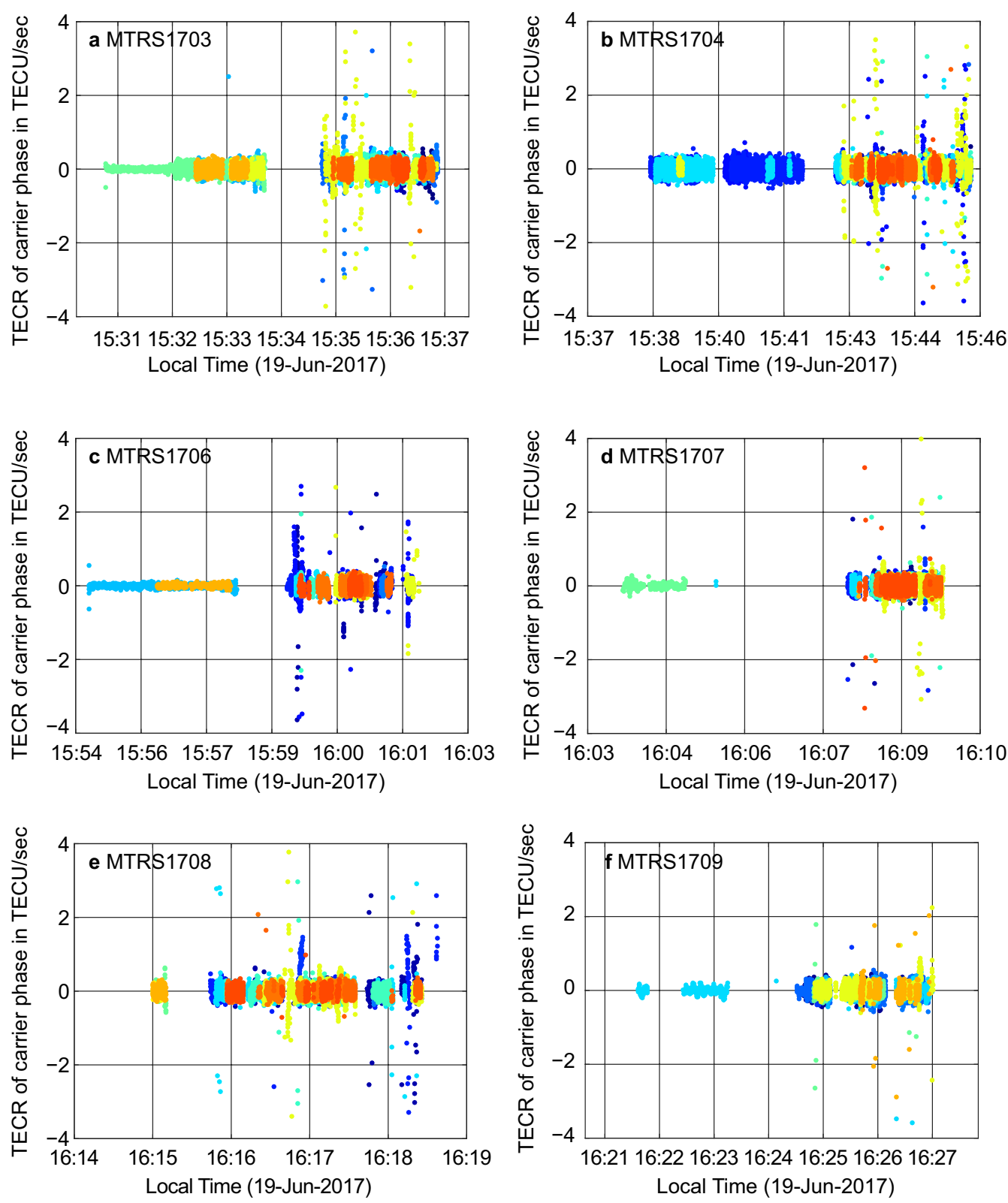

$$
\begin{aligned}
& \bullet \text { G01 • G02 •G03 • G06 • G07 •G11 •G17 • G19 • G22 } \\
& \text { - G28 - G30 }
\end{aligned}
$$

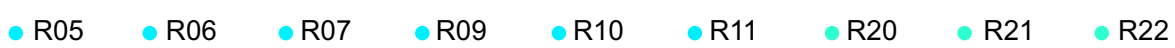

$$
\begin{aligned}
& \text { E08 E18 } \bullet \text { E22 } \bullet \text { E30 }
\end{aligned}
$$

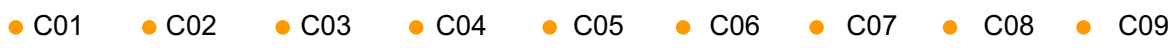

$$
\begin{aligned}
& \text { - } \mathrm{C} 10 \cdot \mathrm{C} 13 \cdot \mathrm{C} 14
\end{aligned}
$$

Fig. 7 TECR derived from six test datasets on carrier phase measurements. They were collected on the moving MTR train and showed in (a-f). The MTRS170x implies that TECR was observed on the MTR train and were derived from the $x$-th session on the 170th day of year 

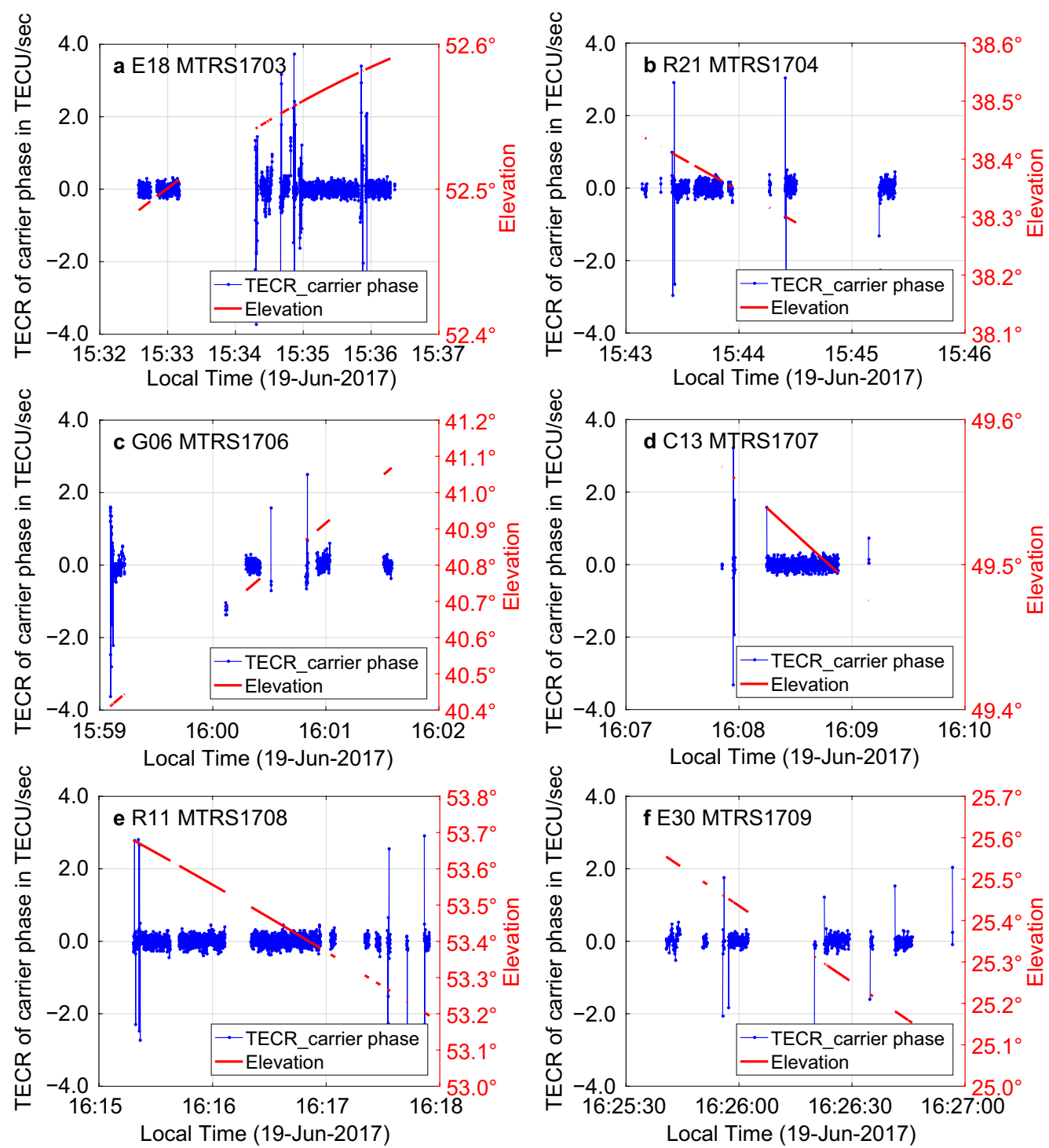

Fig. 8 TECR derived from six different satellites with the corresponding satellite elevations. The results are presented in (a-f). The time format is HH:MM (or HH:MM:SS because of different time durations)

a consecutive tracking arc. The TECR anomalies always appear in the re-tracking stage due to the blockage of buildings, poles, and trees. According to the previous studies from other researchers, the receiver architecture design is responsible for these TECR anomalies (Xie \& Petovello, 2010). When a receiver loses tracking of a satellite, the acquisition process must be performed again to reacquire the satellite (Gardner, 2005). An initial error, namely phase error, will be introduced into the carrier phase measurements in the tracking loop. As a result, the TECR values are severely contaminated by the phase error at the beginning of every new tracking arc.
Furthermore, the carrier-to-noise density ratio (C/ $\mathrm{N}_{0}$ ) and multipath effects on the GNSS signals are presented in the Figs. 9 and 10, respectively. The results show that the $\mathrm{C} / \mathrm{N}_{0}$ of the GNSS signals collected at the moving receiver is always lower than that at the static receiver, especially when the satellite elevation angles are higher than $20^{\circ}$. Specifically, the $\mathrm{C} / \mathrm{N}_{0}$ value at the moving receiver is smaller than that at the static receiver by $9 \mathrm{~dB} \cdot \mathrm{Hz}$ on average for GPS satellites, $7 \mathrm{~dB} \cdot \mathrm{Hz}$ for GLONASS, $12 \mathrm{~dB} \cdot \mathrm{Hz}$ for Galileo, and $5 \mathrm{~dB} \cdot \mathrm{Hz}$ for BDS. In terms of multipath effects, there is no distinct difference between the stationary and moving receivers. Both have 

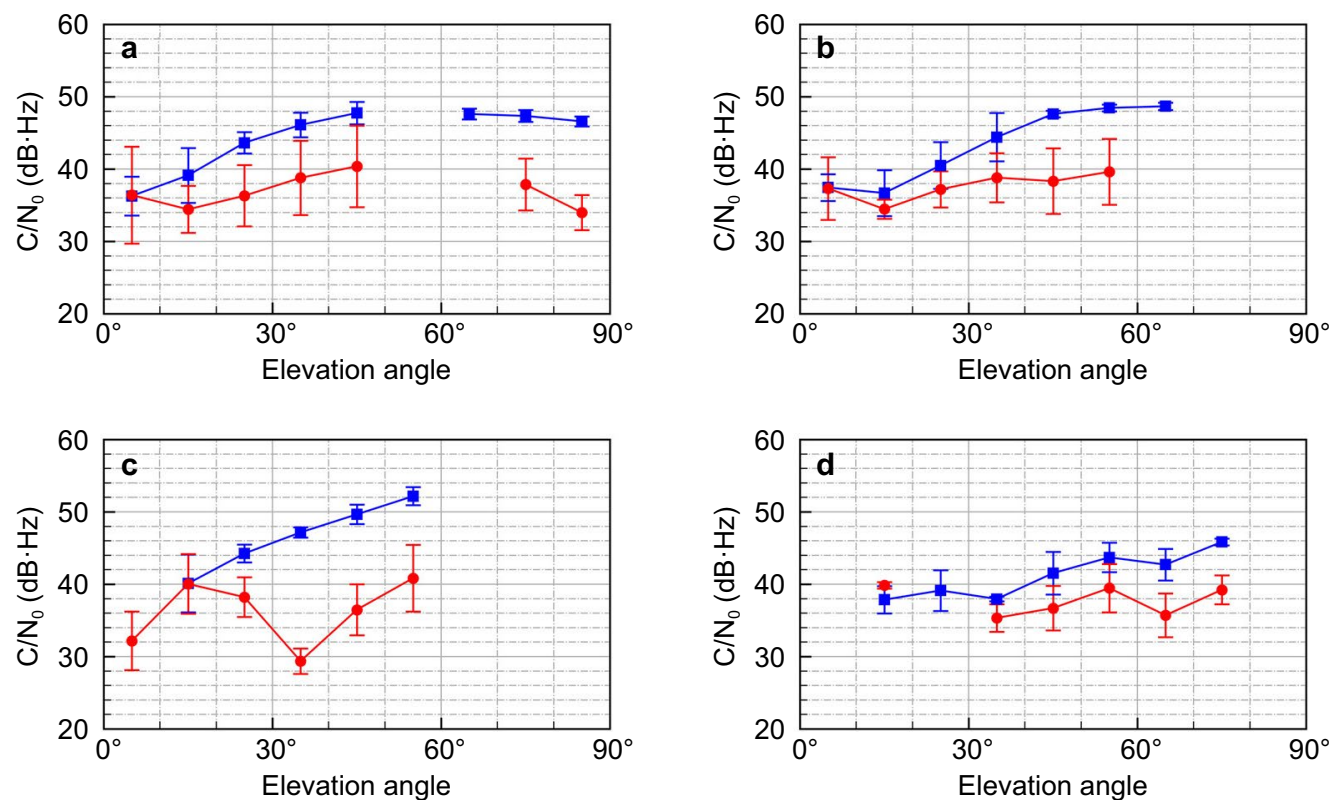

Fig. 9 Averaged carrier-to-noise density ratio $\left(C / N_{0}\right)$ with the standard deviation at different elevation angles for GPS in (a), GLONASS in (b), Galileo in (c), and BDS in (d) for the stationary receiver (blue line) and the moving receiver (red line). The error bars around the data points represent the $\pm 1 \sigma$ standard deviation
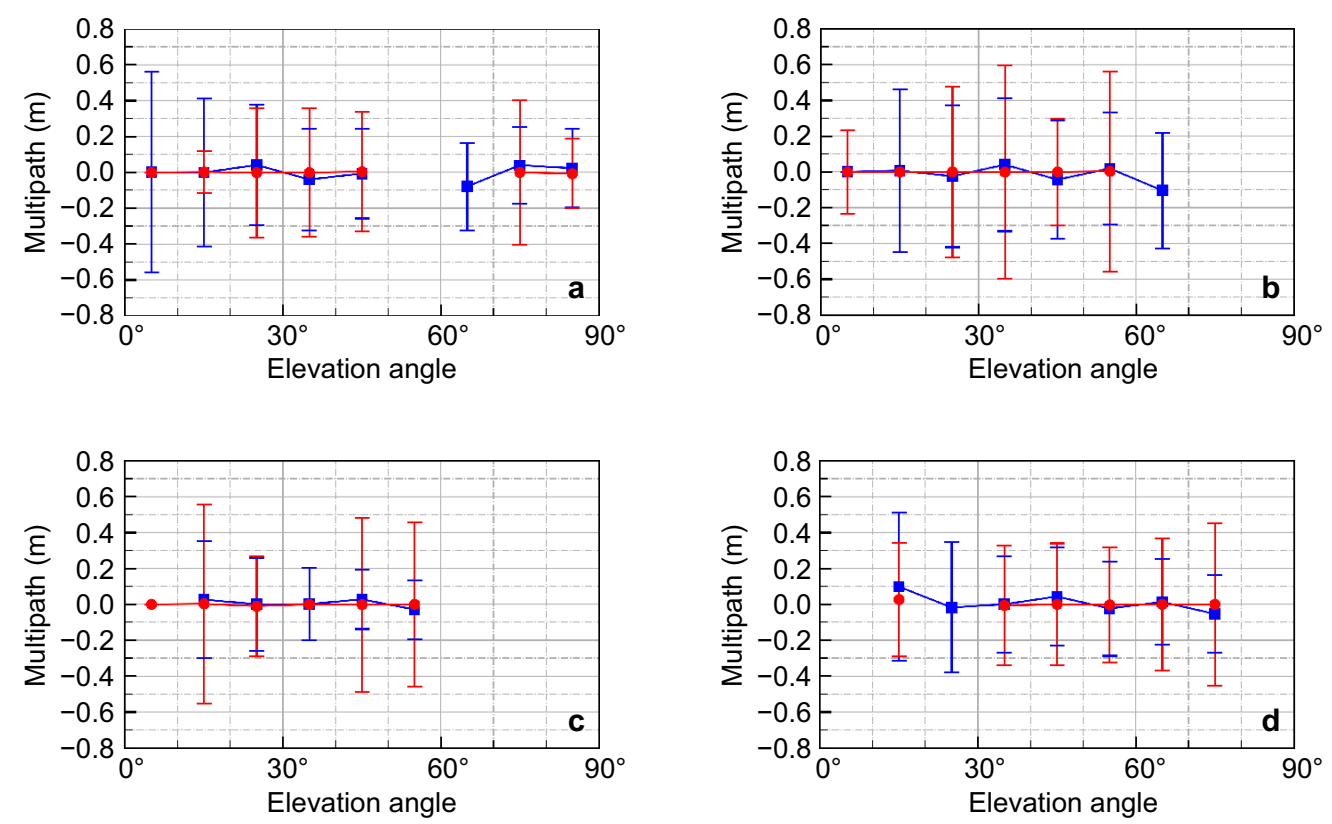

Fig. 10 Averaged multipath effects with standard deviation at different elevation angles for GPS in (a), GLONASS in (b), Galileo in (c), and BDS in (d) for the stationary receiver (blue line) and the moving receiver (red line). The error bars around the data points represent the $\pm 1 \sigma$ standard deviation

the similar mean and standard deviation values, i.e. 0.00 and $0.35 \mathrm{~m}$, respectively. This result confirms that the complicated observation environment in the train leads to the decay or even loss of tracked signals, which results in the anomalies in the TECR values. 

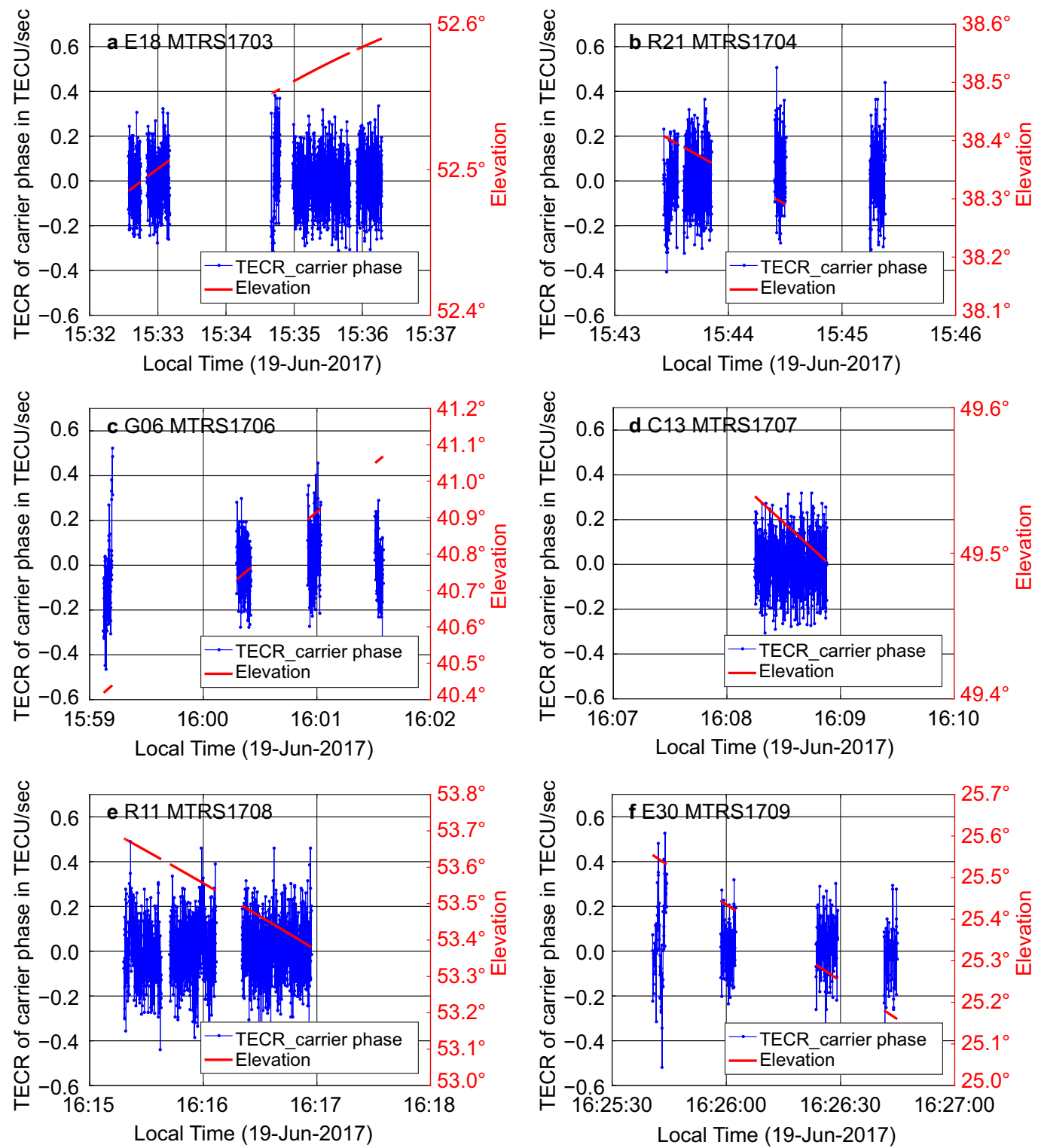

Fig. 11 TECR derived from six randomly selected satellites after applying the generalized ESD test with $\alpha=0.05, r=40$. The results are presented in (a-f)

\section{Outlier elimination using the generalized extreme studentized deviate test}

In Fig. 9, a considerable number of TECR anomalies present in the TECR results of each satellite. In order to eliminate these TECR anomalies, the generalized Extreme Studentized Deviate (ESD) test was introduced due to its well-performed capability of detecting one or more anomalies in a univariate data set that follows an approximately normal distribution (Rosner, 1983).

The generalized ESD test can be defined for the hypothesis:
$\mathrm{H}_{0}$ : There are no outliers in the data set.

$\mathrm{H}_{1}$ : There are up to $\mathrm{r}$ outliers in the data set.

The test statistic can be calculated by:

$$
R_{i}=\frac{\max _{i}\left|x_{i}-\bar{x}\right|}{s}
$$

where $\bar{x}$ and $s$ denote the sample mean and sample standard deviation, respectively. Under the assumption of approximately normal distribution, the test statistic $R_{i}(i=1,2, \ldots, r)$ follows a t-distribution. Given a significance level $\alpha$, the critical values $\lambda_{i}$ can be computed as: 

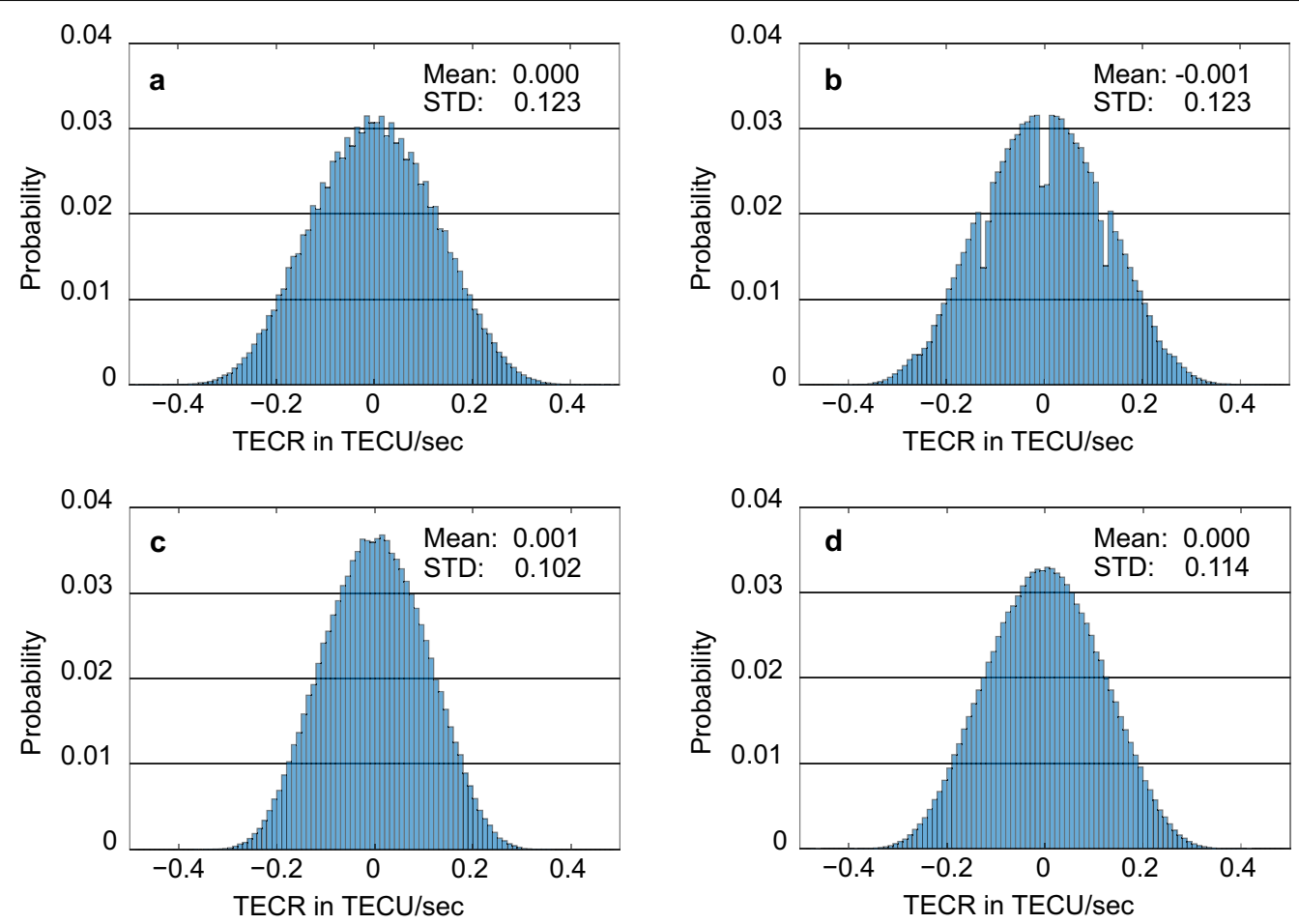

Fig. 12 Probability density distribution of the TECR derived from carrier phase measurements of GPS in (a), GLONASS in (b), Galileo in (c), and BDS in (d) collected at the static station

$$
\lambda_{i}=\frac{(n-i) t_{p, n-i-1}}{\sqrt{\left(n-i-1+t_{p, n-i-1}^{2}\right)(n-i+1)}} i=1,2, \ldots, r
$$

where $t_{p, n-i-1}$ is the $100 p$ percentage point from the $\mathrm{t}$-distribution with $(n-i-1)$ degrees of freedom and $p=1-\frac{\alpha}{2(n-i+1)}$. The number of outliers is determined by finding the largest $i$ which satisfies $R_{i}>\lambda_{i}$.

In the generalized ESD test, the maximum value of $r$ (total of outliers) is determined according to the dataset. Before the test, we set the maximum value of $r$ as 40. The analysis shows the actual number of outliers was smaller than the predefined 40. Assuming the carrier phase measurements have the normal distribution with mean $\mu$ and variance $\sigma^{2}$, as well as every measurement is independent. Then, the TECR values also follow the normal distribution with mean 0 and variance $2\left(\frac{f_{1}^{2}}{40.3 \times 10^{16}(\gamma-1) \Delta t}\right)^{2}\left(\lambda_{1}^{2}+\lambda_{2}^{2}\right) \sigma^{2}$. Figure 11 illustrates the TECR results by applying the generalized ESD test to original TECR values. It is clear to see that most TECR anomalies

Table 3 Statistics of mean and standard deviation of the TECR values derived from carrier phase observations collected from different GNSS systems at both static station and moving MTR train

\begin{tabular}{|c|c|c|c|c|c|c|c|c|}
\hline \multirow[t]{2}{*}{ Items } & \multicolumn{2}{|c|}{$\begin{array}{l}\text { Accuracy from GPS in TECU/ } \\
\text { sec }\end{array}$} & \multicolumn{2}{|c|}{$\begin{array}{l}\text { Accuracy from GLONASS in } \\
\text { TECU/sec }\end{array}$} & \multicolumn{2}{|c|}{$\begin{array}{l}\text { Accuracy from Galileo in } \\
\text { TECU/sec }\end{array}$} & \multicolumn{2}{|c|}{$\begin{array}{l}\text { Accuracy from BDS in } \\
\mathrm{TECU} / \mathrm{sec}\end{array}$} \\
\hline & Mean & STD & Mean & STD & Mean & STD & Mean & STD \\
\hline Static station & 0.000 & 0.123 & -0.001 & 0.123 & 0.001 & 0.102 & 0.000 & 0.114 \\
\hline MTRS1703 & -0.001 & 0.145 & -0.005 & 0.159 & -0.003 & 0.118 & 0.003 & 0.129 \\
\hline MTRS1704 & 0.002 & 0.149 & 0.003 & 0.140 & 0.001 & 0.126 & 0.004 & 0.135 \\
\hline MTRS1706 & -0.007 & 0.146 & -0.000 & 0.130 & -0.005 & 0.120 & -0.000 & 0.123 \\
\hline MTRS1707 & -0.001 & 0.130 & -0.001 & 0.128 & -0.006 & 0.183 & 0.002 & 0.124 \\
\hline MTRS1708 & 0.007 & 0.194 & 0.004 & 0.138 & -0.014 & 0.168 & 0.001 & 0.125 \\
\hline MTRS1709 & 0.001 & 0.149 & 0.002 & 0.141 & 0.009 & 0.127 & - & - \\
\hline Overall & 0.000 & 0.152 & 0.000 & 0.139 & -0.003 & 0.140 & 0.002 & 0.127 \\
\hline
\end{tabular}



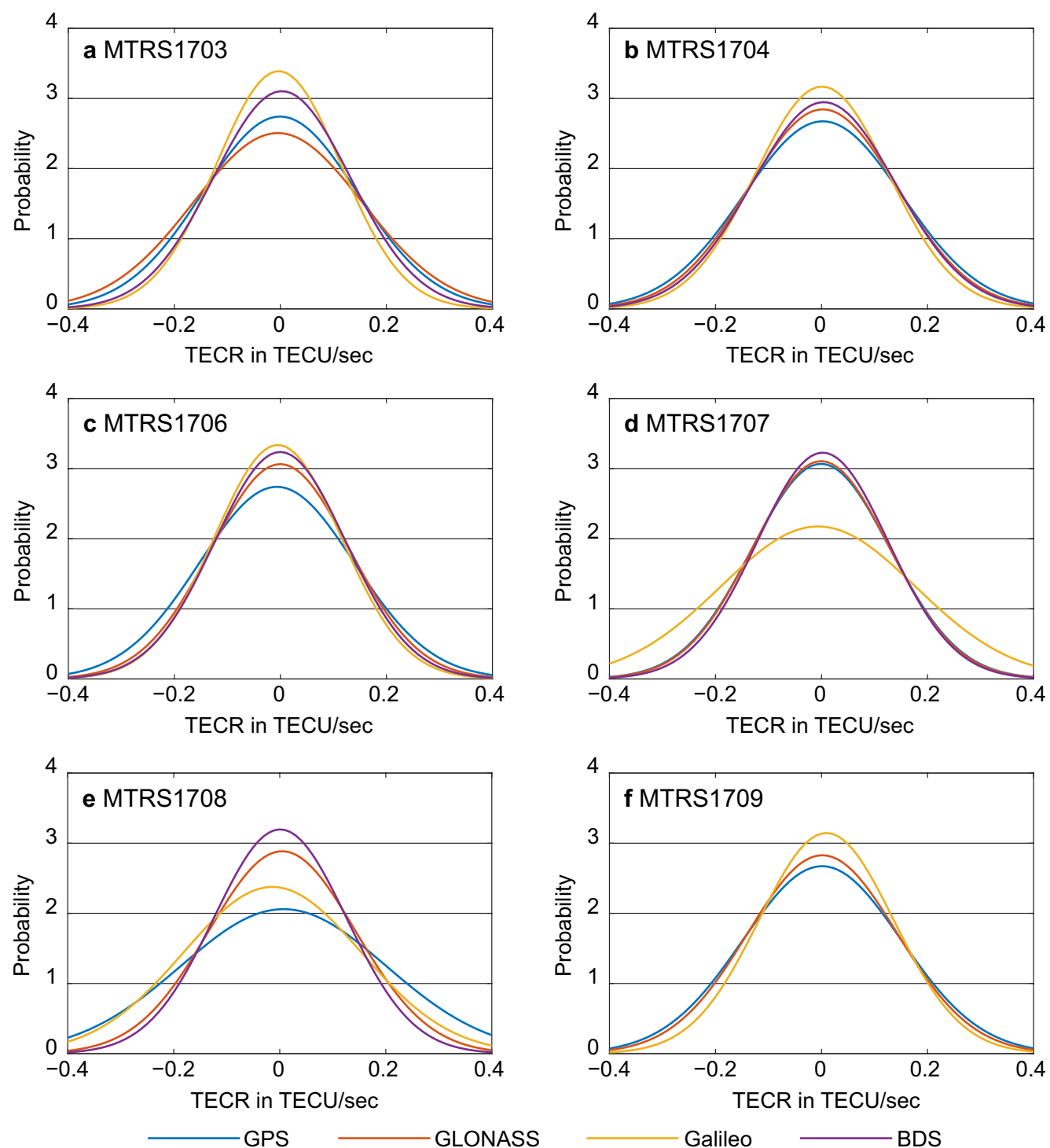

Fig. 13 Probability density functions of the TECR derived from the moving receiver for six travels $(\mathbf{a}-\mathbf{f})$. They are calculated from the carrier phase measurements collected at the moving station on the MTR train. The probability density function for BDS in MTRS1709 is not displayed because of inadequate observations

have been removed after the implementation of the generalized ESD test.

\section{TECR statistic characteristics}

Figure 12 shows the probability distribution of the TECR derived from the SS receiver on the carrier phase measurements. It should be noted that the data have not been downsampled to $1 \mathrm{~s}$, and the original data with the sampling rate of $20 \mathrm{~Hz}$ is used. The TECR derived from four GNSS systems have almost the same mean value of $0.000 \mathrm{TECU} / \mathrm{sec}$, and their standard deviations are in the range of 0.102 to
$0.123 \mathrm{TECU} / \mathrm{sec}$. The TECR values derived from the Galileo satellites have the smallest standard deviation of 0.102 TECU/sec followed by BDS-based TECR, 0.114 TECU/ sec. The TECR values derived from the GPS and GLONASS satellites have the same standard deviation of $0.123 \mathrm{TECU} /$ sec. Figure 13 illustrates the probability density functions of the TECR derived from six datasets collected at the MS receiver. The detailed statistical results are shown in Table 3.

Their means change within -0.014 to $0.009 \mathrm{TECU} /$ sec, and their standard deviations are within 0.118 to $0.194 \mathrm{TECU} / \mathrm{sec}$. The standard deviation for the Galileobased TECR in the MTRS1707 and MTRS1708 datasets 

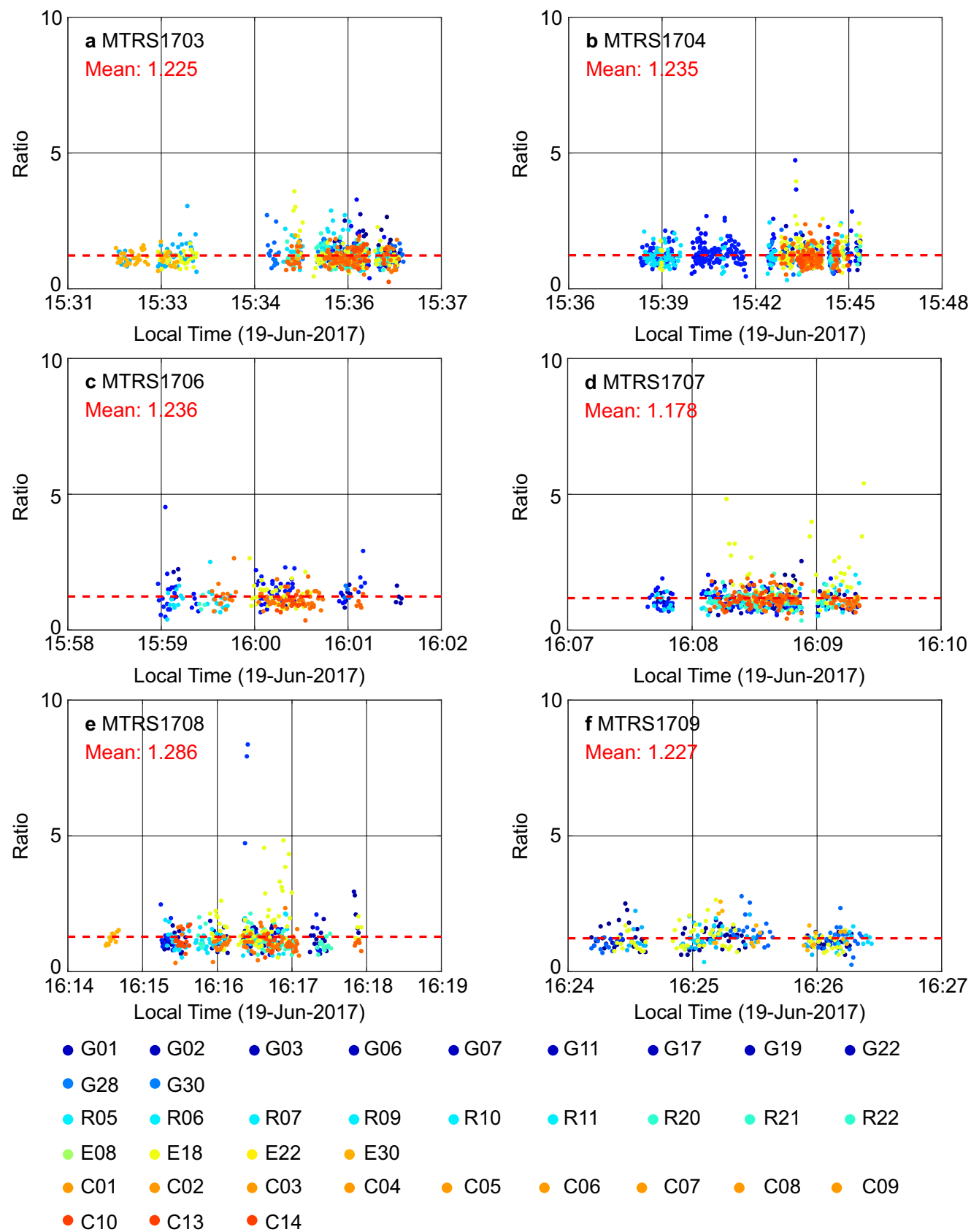

Fig. 14 Ratio between the RMS derived from the moving station and static station for each satellite. The results of the six travels are presented in $(\mathbf{a}-\mathbf{f})$. The ratio value is calculated at the interval of $1 \mathrm{~s}$, which means $\mathrm{N}$ is equal to 20 . The red dashed line denotes the average value of the ratios of all the satellites

is slightly larger than the standard deviation in the other datasets. One possible reason for this result is that the ionospheric situation was changing with time. Another possible reason is that observation condition inside the MTR train was different in each journey. The TECR derived from BDS has the smallest standard deviation of $0.127 \mathrm{TECU} / \mathrm{sec}$. The TECR derived from the GPS is a little higher, with standard deviations of 0.152 TECR/ sec. The standard deviations of the TECR from the GLONASS and Galileo are almost the same, being 0.139 $\mathrm{TECU} / \mathrm{sec}$ and $0.140 \mathrm{TECR} / \mathrm{sec}$, respectively.

The mean TECR from the moving receiver is larger than that from the stationary receiver and varies in each travel. In terms of standard deviation, the result from the moving 
receiver increases by $23 \%, 13 \%, 37 \%$, and $11 \%$ for GPS, GLONASS, Galileo, and BDS, respectively, with respect to that from the stationary receiver.

\section{Assessment of the TECR derived from the moving MTR train}

The properties of the TECR derived from the SS and MS receivers have been discussed. To assess the TECR calculated from the MS receiver, the assessment equation is introduced as follows:

$$
\text { Ratio }=\frac{R M S_{m s}}{R M S_{s s}}
$$

where $R M S_{m s}$ and $R M S_{s s}$ are the RMS of the TECR derived from the MS and SS receivers. The RMS can be calculated from the following equation:

$$
R M S=\sqrt{\frac{\sum\left(T E C R_{i}\right)^{2}}{N}}
$$

where $N$ is the total number of the observations within $1 \mathrm{~s}$ and $i$ is the index of the observations $(i=1,2, \ldots, 20)$.

Figure 14 demonstrates the ratio of the six datasets at the interval of 1 second. The maximum ratio of G22 can reach up to around 8.0 displayed in MTRS1708. For the results of other travels, the maximum ratios are about 6.0. However, the average ratio is about 1.23 for the six journeys, and the ratios of six journeys are 1.225, 1.235, $1.236,1.178,1.286$ and 1.227. The ratios calculated from the six journeys suggest that the train-based kinematic TECR results are consistently higher than the groundbased static TECR results by around $23 \%$. It is acceptable for the ionospheric monitoring. Yang and Liu (2016a) showed a rapid TECR change during the 2012 tropical cyclone Tembin passing in Hong Kong. The maximum TECR can reach up to 16 TECU/sec. Pi et al. (1997) showed that $2 \mathrm{TECU} / \mathrm{min}$ fluctuation could be observed in a low latitude region, and a GPS scintillation event can produce up to $20 \mathrm{TECU} / \mathrm{min}$ fluctuation. Therefore, it is possible to measure those TECR variations using the train-based kinematic observations. Furthermore, they can be utilized to monitor the ionospheric situation to complement the ground-based TECR observation.

\section{Conclusion}

Considering the insufficient and uneven distribution of GNSS ionospheric monitoring networks, we propose a novel approach to monitor the ionosphere. This new method based on a fast-moving train platform can complement the traditional ground-based TECR monitoring method.

We studied the train-based dynamic TECR monitoring from three aspects: (1) analysis of the TECR derived from pseudorange and carrier phase measurements collected at both SS and MS receivers; (2) the statistical properties of TECR derived from the data of the four GNSS systems; (3) assessment of the TECR derived from the MS receiver with respect to the TECR from the SS receiver. We found that the accuracy of the TECR on the pseudorange measurements collected at the SS receiver is approximately 2.5 times larger than the theoretical value, while the accuracy of the TECR on the carrier phase measurements is similar to the theoretical one. This can probably be attributed to the multipath effect in the pseudorange measurements in the observation environment.

Furthermore, the characteristic of the TECR values from the four GNSS systems was analyzed. For the SS receiver, the TECR values from different GNSS systems are almost the same. All of them had a mean value of $0.000 \mathrm{TECU} / \mathrm{sec}$ and the standard deviations were within the range of 0.102 to $0.123 \mathrm{TECU} / \mathrm{sec}$. For the MS receiver, the TECR values from six journeys were analyzed. The TECR mean was close to 0.000 TECU/ sec. However, their standard deviations were larger than those calculated from the SS receiver by $23 \%, 13 \%$, $37 \%$ and $11 \%$ for the GPS, GLONASS, Galileo, and BDS, respectively.

Lastly, the RMS error of the TECR data collected at the MS receiver is approximately $23 \%$ larger than that calculated from the SS receiver. This can probably be attributed to the decrease of the carrier-to-noise density ratio $\left(C / N_{0}\right)$ of the GNSS signals due to the window glass of the train as well as the larger multipath effects. The slightly different observation conditions could also contribute to the larger RMS error.

\section{Acknowledgements}

The authors would like to acknowledge the support from the Key Program of the National Natural Science Foundation of China (NSFC) and the Hong Kong Research Grants Council (RGC).

\section{Authors' contributions}

All authors contributed to the study conception and design. Material preparation, data collection and analysis were performed by SY. The first draft of the manuscript was written by SY. The critical review and revision were completed by ZL. ZL incubated the idea of this work, supervised the project, and provided project funding support to this work. All authors commented on previous versions of the manuscript. All authors read and approved the final manuscript.

\section{Funding}

The grant support to Zhizhao Liu from the Key Program of the National Natural Science Foundation of China (NSFC) project (No:: 41730109) is acknowledged. The grant supports to Zhizhao Liu from the Hong Kong Research Grants Council (RGC) project (B-Q61L PolyU 152222/17E) are thanked. The Emerging Frontier Area (EFA) Scheme of Research Institute for Sustainable Urban Development (RISUD) of the Hong Kong Polytechnic University under Grant 1-BBWJ is also acknowledged.

\section{Availability of data and materials}

The datasets used and analyzed during the current study are available from the corresponding author on request. 


\section{Declarations}

\section{Competing interests}

The authors declare that they have no competing interests.

Received: 4 May 2021 Accepted: 29 July 2021

Published online: 20 September 2021

\section{References}

Aarons, J., \& Lin, B. (1999). Development of high latitude phase fluctuations during the January 10, April 10-11, and May 15, 1997 magnetic storms. Journal of Atmospheric and Solar-Terrestrial Physics, 61(3-4), 309-327. https://doi.org/10.1016/S1364-6826(98)00131-X

Adeniyi, J. O., Doherty, P. H., Oladipo, O. A., \& Bolaji, O. (2014). Magnetic storm effects on the variation of TEC over Ilorin an equatorial station. Radio Science, 49(12), 1245-1253. https://doi.org/10.1002/2014RS005404

Aquino, M., Moore, T., Dodson, A., Waugh, S., Souter, J., \& Rodrigues, F. S. (2005). Implications of ionospheric scintillation for GNSS users in Northern Europe. Journal of Navigation, 58(2), 241-256. https://doi.org/10.1017/ s0373463305003218

Arikan, F., Erol, C. B., \& Arikan, O. (2003). Regularized estimation of vertical total electron content from Global Positioning System data. Journal of Geophysics Research-Space Physics, 108(A12), 12. https://doi.org/10.1029/ 2002ja009605

Bergeot, N., Chevalier, J.-M., Bruyninx, C., Pottiaux, E., Aerts, W., Baire, Q., Legrand, J., Defraigne, P., \& Huang, W. (2014). Near real-time ionospheric monitoring over Europe at the Royal Observatory of Belgium using GNSS data. Journal of Space Weather Space Clim. https://doi.org/10.1051/swsc/ 2014028

Bernhardt, P. A., Siefring, C. L., Galysh, I. J., Rodilosso, T. F., Koch, D. E., MacDonald, T. L., Wilkens, M. R., \& Landis, G. P. (2006). Ionospheric applications of the scintillation and tomography receiver in space (CITRIS) mission when used with the DORIS radio beacon network. Journal of Geodesy, 80(8-11), 473-485. https://doi.org/10.1007/s00190-006-0064-6

Cai, C., Liu, Z., Xia, P., \& Dai, W. (2013). Cycle slip detection and repair for undifferenced GPS observations under high ionospheric activity. GPS Solution, 17(2), 247-260. https://doi.org/10.1007/s10291-012-0275-7

Chen, W., Gao, S., Hu, C., Chen, Y., \& Ding, X. (2008). Effects of ionospheric disturbances on GPS observation in low latitude area. GPS Solution, 12(1), 33-41. https://doi.org/10.1007/s10291-007-0062-z

Chen, W., Lee, C., Chu, F., \& Teh, W. (2017). GPS TEC fluctuations over Tromso, Norway, in the solar minimum. Terrestrial Atmospheric and Ocean Science, 28(6), 993-1008. https://doi.org/10.3319/TAO.2017.04.24.01

Czerniak, R. J., \& Reilly, J. P. (1998). Applications of GPS for surveying and other positioning needs in departments of transportation. National Academy Press.

Davies, K. (1990). Ionospheric radio. Peter Peregrinus.

Feltens, J. (2007). Development of a new three-dimensional mathematical ionosphere model at European Space Agency/European Space Operations Centre. Space Weather. https://doi.org/10.1029/2006SW000294

Gardner, F. M. (2005). Phaselock Techniques. Wiley.

Ghoddousi-Fard, R., Héroux, P., Danskin, D., \& Boteler, D. (2011). Developing a GPS TEC mapping service over Canada. Space Weather. https://doi.org/10. 1029/2010SW000621

Grejner-Brzezinska, D. A., Kashani, I., Wielgosz, P., Smith, D. A., Spencer, P. S. J., Robertson, D. S., \& Mader, G. L. (2007). Efficiency and Reliability of Ambiguity Resolution in Network-Based Real-Time Kinematic GPS. Journal of Surveying Engineering, 133(2), 56-65. https://doi.org/10.1061/(ASCE)07339453(2007)133:2(56)

Gulyaeva, T., \& Arikan, F. (2017). Statistical discrimination of global post-seismic ionosphere effects under geomagnetic quiet and storm conditions. Geomat Nat Hazards Risk, 8(2), 509-524. https://doi.org/10.1080/19475 705.2016 .1246483
Hernández-Pajares, M., Juan, J. M., Sanz, J., Orus, R., Garcia-Rigo, A., Feltens, J., Komjathy, A., Schaer, S. C., \& Krankowski, A. (2009). The IGS VTEC maps: A reliable source of ionospheric information since 1998. Journal of Geodesy, 83(3), 263-275. https://doi.org/10.1007/s00190-008-0266-1

Hernández-Pajares, M., Roma-Dollase, D., Krankowski, A., García-Rigo, A., \& Orús-Pérez, R. (2017). Methodology and consistency of slant and vertical assessments for ionospheric electron content models. Journal of Geodesy, 91(12), 1405-1414. https://doi.org/10.1007/ s00190-017-1032-z

Jin, S., Occhipinti, G., \& Jin, R. (2015). GNSS ionospheric seismology: Recent observation evidences and characteristics. Earth Science Reviews, 147, 54-64. https://doi.org/10.1016/j.earscirev.2015.05.003

Kong, J., Yao, Y., Xu, Y., Kuo, C., Zhang, L., Liu, L., \& Zhai, C. (2017). A clear link connecting the troposphere and ionosphere: Ionospheric reponses to the 2015 Typhoon Dujuan. Journal of Geodesy, 91(9), 1087-1097. https://doi.org/10.1007/s00190-017-1011-4

Leick, A., Rapoport, L., \& Tatarnikov, D. (2015). GPS Satellite Surveying (3rd ed.). Wiley.

Li, B., Shen, Y., Feng, Y., Gao, W., \& Yang, L. (2014). GNSS ambiguity resolution with controllable failure rate for long baseline network RTK. Journal of Geodesy, 88(2), 99-112. https://doi.org/10.1007/s00190-013-0670-z

Li, Z., Wang, N., Hernández-Pajares, M., Yuan, Y., Krankowski, A., Liu, A., Zha, J., García-Rigo, A., Roma-Dollase, D., Yang, H., Laurichesse, D., \& Blot, A. (2020). IGS real-time service for global ionospheric total electron content modeling. Journal of Geodesy, 94(3), 32. https://doi.org/10. 1007/s00190-020-01360-0

Li, Z., Yuan, Y., Wang, N., Hernandez-Pajares, M., \& Huo, X. (2015). SHPTS: Towards a new method for generating precise global ionospheric TEC map based on spherical harmonic and generalized trigonometric series functions. Journal of Geodesy, 89(4), 331-345. https://doi.org/10. 1007/s00190-014-0778-9

Liu, Z. (2011). A new automated cycle slip detection and repair method for a single dual-frequency GPS receiver. Journal of Geodesy, 85(3), 171-183. https://doi.org/10.1007/s00190-010-0426-y

Liu, Z., \& Gao, Y. (2004). Ionospheric TEC predictions over a local area GPS reference network. GPS Solut, 8(1), 23-29. https://doi.org/10.1007/ s10291-004-0082-X

Liu, Z., Gong, Y., \& Zhou, L. (2020). Impact of China's high speed train window glass on GNSS signals and positioning performance. Satellite Navigation, 1(1), 14. https://doi.org/10.1186/s43020-020-00013-z

Mannucci, A. J., Wilson, B. D., Yuan, D. N., Ho, C. H., Lindqwister, U. J., \& Runge, T. F. (1998). A global mapping technique for GPS-derived ionospheric total electron content measurements. Radio Science, 33, 565-582.

Mendillo, M., Lin, B., \& Aarons, J. (2000). The application of GPS observations to equatorial aeronomy. Radio Science, 35(3), 885-904. https://doi.org/ 10.1029/1999RS002208

Mungufeni, P., Habarulema, J. B., \& Jurua, E. (2016). Trends of ionospheric irregularities over African low latitude region during quiet geomagnetic conditions. J Atmospheric Sol-Terr Phys, 138-139, 261-267. https:// doi.org/10.1016/j.jastp.2016.01.015

Opperman, B. D. L., Cilliers, P. J., McKinnell, L. A., \& Haggard, R. (2007). Development of a regional GPS-based ionospheric TEC model for South Africa. Advances in Space Research, 39(5), 808-815. https://doi.org/10. 1016/j.asr.2007.02.026

Orús, R., Hernández-Pajares, M., Juan, J. M., \& Sanz, J. (2005). Improvement of global ionospheric VTEC maps by using kriging interpolation technique. Journal of Atmospheric Solar-Terrestrial Physics, 67(16), 1598-1609. https:// doi.org/10.1016/j.jastp.2005.07.017

Pi, X., Mannucci, A. J., Lindqwister, U. J., \& Ho, C. M. (1997). Monitoring of global ionospheric irregularities using the Worldwide GPS Network. Geophysical Research Letters, 24(18), 2283-2286. https://doi.org/10.1029/97GL02273

Roma-Dollase, D., Hernández-Pajares, M., Krankowski, A., Kotulak, K., Ghoddousi-Fard, R., Yuan, Y., Li, Z., Zhang, H., Shi, C., Wang, C., Feltens, J., Vergados, P., Komjathy, A., Schaer, S., García-Rigo, A., \& Gómez-Cama, J. M. (2018). Consistency of seven different GNSS global ionospheric mapping 
techniques during one solar cycle. Journal of Geodesy, 92(6), 691-706. https://doi.org/10.1007/s00190-017-1088-9

Rosner, B. (1983). Percentage points for a generalized ESD many-outlier procedure. Technometrics, 25(2), 165-172. https://doi.org/10.1080/0040 706.1983.10487848

Schaer S (1999) Mapping and predicting the Earth's ionosphere using the Global Positioning System, Ph.D. Dissertation Astronomical Institute, University of Berne, Berne, Switzerland, 25 March

Sreeja, V., Aquino, M. \& Elmas, Z. G. (2011). Impact of ionospheric scintillation on GNSS receiver tracking performance over Latin America: Introducing the concept of tracking jitter variance maps. Space Weather International Journal of Research Applications, 9(10), 1-6. https://doi.org/10.1029/2011s w000707

Tapping, K. F. (2013). The $10.7 \mathrm{~cm}$ solar radio flux (F10. 7). Space Weather, 11(7), 394-406. https://doi.org/10.1002/swe.20064

Tariku, Y. A. (2015). Patterns of GPS-TEC variation over low-latitude regions (African sector) during the deep solar minimum (2008 to 2009) and solar maximum (2012 to 2013) phases. Earth, Planets and Space, 67(1), 35. https://doi.org/10.1186/s40623-015-0206-2

Vuković J, Kos T (2016) lonospheric spatial and temporal gradients for disturbance characterization. In: Proc. IEEE/ENC 2016, European Navigation Conference, Helsinki, Finland, May 30-June 2, 1-4. https://doi.org/10. 1109/EURONAV.2016.7530564

Wanninger L (1993) lonospheric monitoring using IGS data. In: Proceedings of the 1993 IGS Workshop. Astronomical Institute, University of Berne, Berne, Switzerland, March 25-26
Xie P, Petovello MG (2010) Improving carrier phase reacquisition using advanced receiver architectures. In: Proc. IEEE/ION PLANS 2010, Institute of Navigation, Indian Wells, CA, USA, May 4-6, 728-736. https://doi.org/ 10.1109/PLANS.2010.5507258

Yang, Z., \& Liu, Z. (2016a). Observational study of ionospheric irregularities and GPS scintillations associated with the 2012 tropical cyclone Tembin passing Hong Kong. Journal of Geophysics Research Space Physics, 121(5), 4705-4717. https://doi.org/10.1002/2016JA022398

Yang, Z., \& Liu, Z. (2016b). Correlation between ROTI and lonospheric Scintillation Indices using Hong Kong low-latitude GPS data. GPS Solut, 20(4), 815-824. https://doi.org/10.1007/s10291-015-0492-y

Yang, Z., Song, S., Jiao, E., Chen, G., Xue, J., Zhou, W., \& Zhu, W. (2016). Ionospheric tomography based on GNSS observations of the CMONOC: performance in the topside ionosphere. GPS Solut, 21(2), 363-375. https:// doi.org/10.1007/s10291-016-0526-0

Zhao, J., Hernández-Pajares, M., Li, Z., Wang, L., \& Yuan, H. (2020). High-rate Doppler-aided cycle slip detection and repair method for low-cost single-frequency receivers. GPS Solut, 24(3), 80. https://doi.org/10.1007/ s10291-020-00993-0

\section{Publisher's Note}

Springer Nature remains neutral with regard to jurisdictional claims in published maps and institutional affiliations.

\section{Submit your manuscript to a SpringerOpen ${ }^{\circ}$ journal and benefit from:}

- Convenient online submission

- Rigorous peer review

- Open access: articles freely available online

- High visibility within the field

- Retaining the copyright to your article

Submit your next manuscript at $\boldsymbol{\nabla}$ springeropen.com 